Mariusz Grasza, Dominik Klimas and Hubert Skrzypczak

\title{
4. ANTI-TERRORIST ACTIONS INVOLVING CBRN MATERIALS
}

The antiterrorism action in CBRN environment is very complicated issue which must involve various sources and services. The main component ot that type of operation are Police special units with PPE and special detection equipment, fire fighters with decontamination pathway as well as other services responsible for CBRN agent neutralization. Exercises in the field of responding to the CBRN event in the context of a terrorist CBRN episode are aimed at systematizing knowledge and focusing the process of preparation of practical services, entities in the area of supporting CBRN specialized activities carried out in the course of counterterrorism activities. The main goal should be to indicate the necessary elements in the process of preparing and conducting AT / CBRN activities, including improving the CBRN detection capability and individual command skills necessary to perform functional duties in the process of preparing and conducting operations in a crisis situation in accordance with the intended use.

The proper scenario of this type of action will be presented based on Polish Anti-terrorist exercise in National Centre of Nuclear Research (NCBJ) in Świerk called Patrol 2015 which verified the readiness of the KSWSiA Contamination Detection \& Alerting system.

The scenario of the exercise was that some radioactive material was released from the MARIA nuclear reactor in result of a terrorist attack. Objectives of the exercise included to check readiness of the relevant services/offices/forces (National Atomic Energy Agency's Radiation Emergency Centre, Otwock County Police Department, Polish Police Headquarters' Duty Officer, Polish Police Headquarters' Bureau of Counter-Terrorist Operations) to react to this threat.

1. The aim of the exercises was to perform CBRN detection activities, $\mathrm{CBRN}$ event management at the operational level in the most-real-world conditions and to develop the right skills and habits that are necessary in counterterrorism activities.

2. In order to increase the realism of the exercise, the actions of the crisis management entities were played, while the terrorist activities were simulated by the police anti-terrorists.

3. The content of the exercises was the execution by participants of the detection in the course of simulated counter-terrorist actions, effective use of the 
acquired knowledge acquired in the course of specialized courses, commanding, planning and conducting logistics activities.

The basic principles of the exercise were:

- unity of individual and team training;

- realism;

- continuity of the exercise.

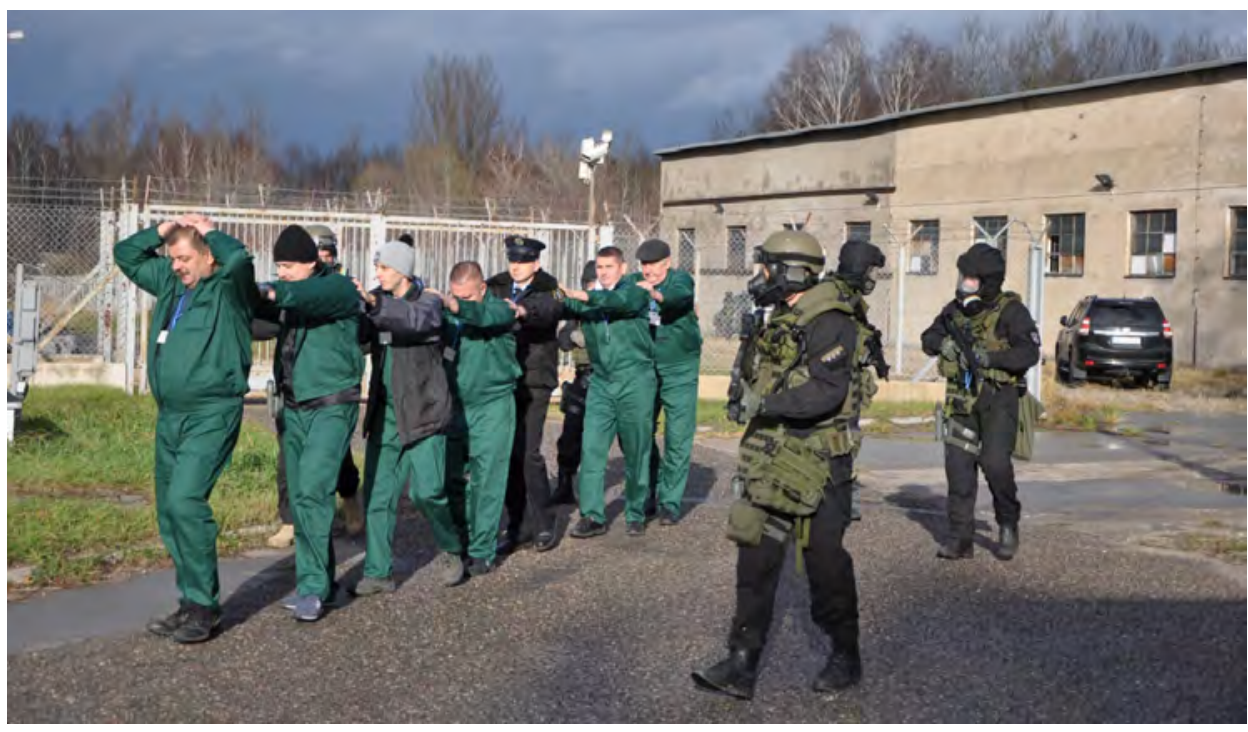

Figure 1. March of arrested people assisted by BOA KGP officers to the place of initial decontamination

The scenario of the episode played in NCBJ assumed the invasion of an armed group of terrorists on the premises of the institute. The service of the facility, which was to constitute a bargaining chip for unknown perpetrators of the offense, was captured. Immediately after the incident was noticed by the patrol of the internal security service, the response procedures provided for such a circumstance were activated. Thanks to that, only a few minutes after the notification, specialized services arrived: the Police, the State Fire Service and the locally based Radioactive Waste Utilization Plant.

After conducting preliminary police arrangements by local police units, a unit specialized in CBRN counter-terrorism operations, Bureu of Counterterrorist Operations of the Police Headquarters (BOA KGP), was established via the Police's duty system.

In accordance with the applicable procedures, the headquarters of the police operation command office was established in a safe place to conduct command and coordination activities at the scene. 
The composition of this command office include:

- directing anti-terrorist activities along with officers carrying out planning and coordination tasks (in this situation);

- the administrator of the nuclear facility;

- commanding the activities of the State Fire Service;

- Police spokesman.

During the action the following activities had been performed:

- evacuation of personnel from the object at risk was carried out;

- establishing the zones with a division into hot, transitional and so-called clean (safe) with the location of possible press bands;

- a safe place has been set for the dislocation of equipment and service necessary to perform initial decontamination;

- the tactics of action for the responding services have been defined, taking into account the means of individual protection and the provision of tactical equipment, including dosimetry devices;

- defined possible action scenarios, including the possibility of spreading contamination and exposure to possible exposure of ionizing radiation.

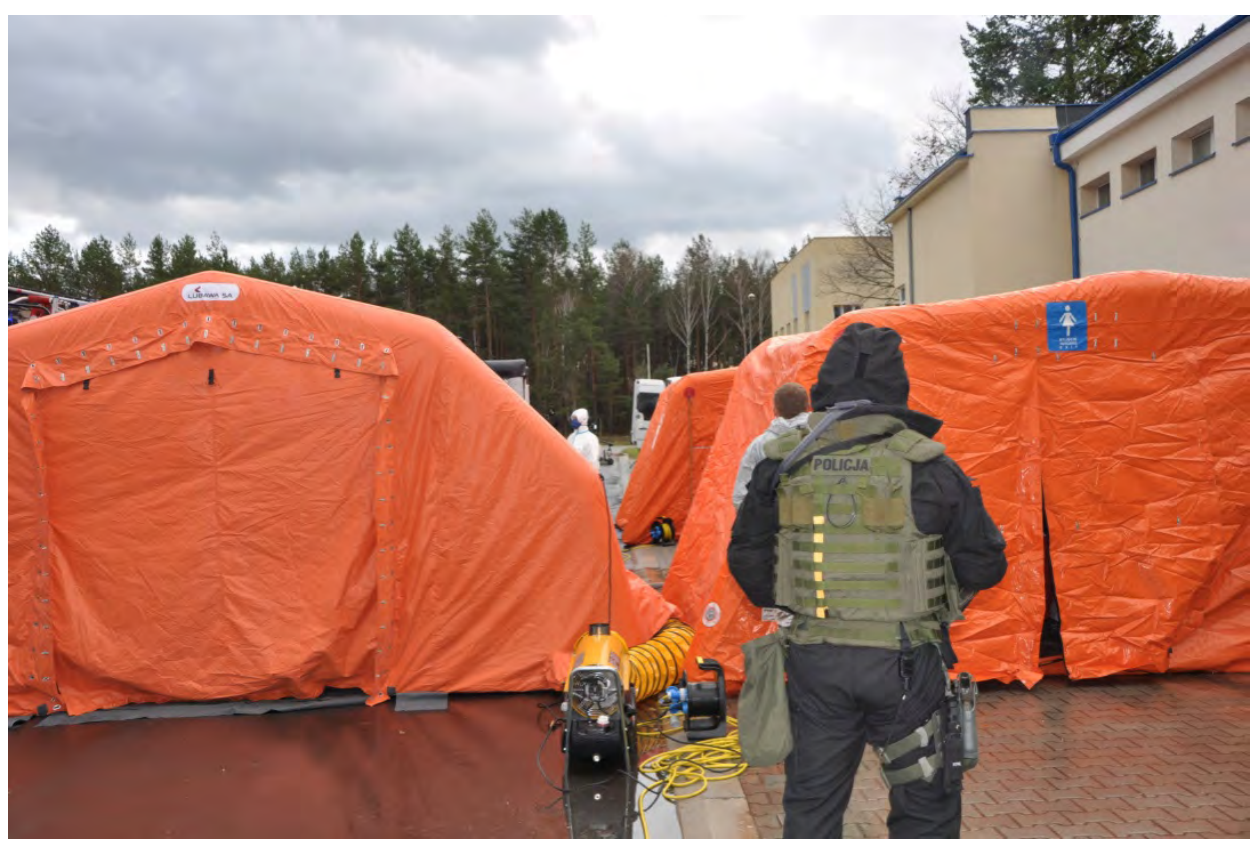

Figure 2. The securing decontamination tents by the officers of the BOA KGP

The initial decontamination was installed by the State Fire Brigade, which had arrived in place, in a configuration enabling safe decontamination of officers, 
hostages and perpetrators of the crime. With particular emphasis on tactics that allow continuous surveillance during its operations over detainees (Fig. 3). An important element was the organization of security for contaminated firearms and specialized equipment of officers carrying out anti-terrorist tasks.

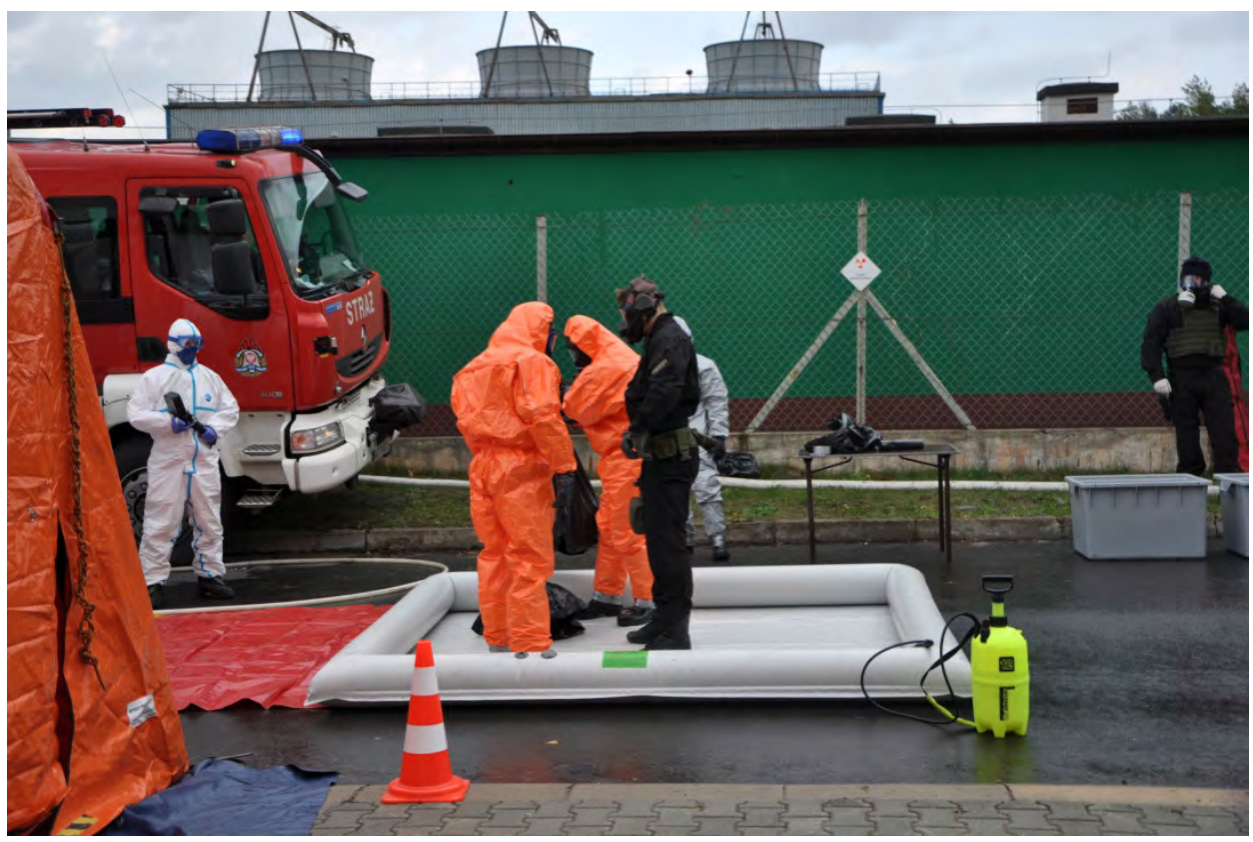

Figure 3. The initial decontamination process under the supervision of the officers of the BOA KGP

In the meantime, monitoring of possible contamination of the action zone was carried out through the use of permanent dosimetry systems located on the site of NCBJ and based on individual equipment of policemen securing access to the danger zone. The officers of BOA KGP also used a robot armed with devices signaling elevated gamma and neutron radiation. The vehicle moved remotely through the hot zone and also enabled the vision to be provided through the cameras in which it was equipped.

A police helicopter equipped with highly specialized optical equipment enabling satellite transmission of a registered online vision directly to the commanding police operation was also ordered. There have been established shooting positions aimed at supporting officers who perform counter-terrorist tasks. In the meantime, it has secured a place for medical assistance to victims that could possibly be contaminated.

At the time of note shot in the facility, where were terrorists and hostage head of counter-terrorism activities decided to launch an immediate assault on 
the building occupied by the perpetrators. Anti-terrorist officers equipped with individual CBRN protection measures (upper respiratory tract protection, body surface) and equipment outside firearms and tactical equipment in an individual dosimeter started a concealed approach to the obiect.

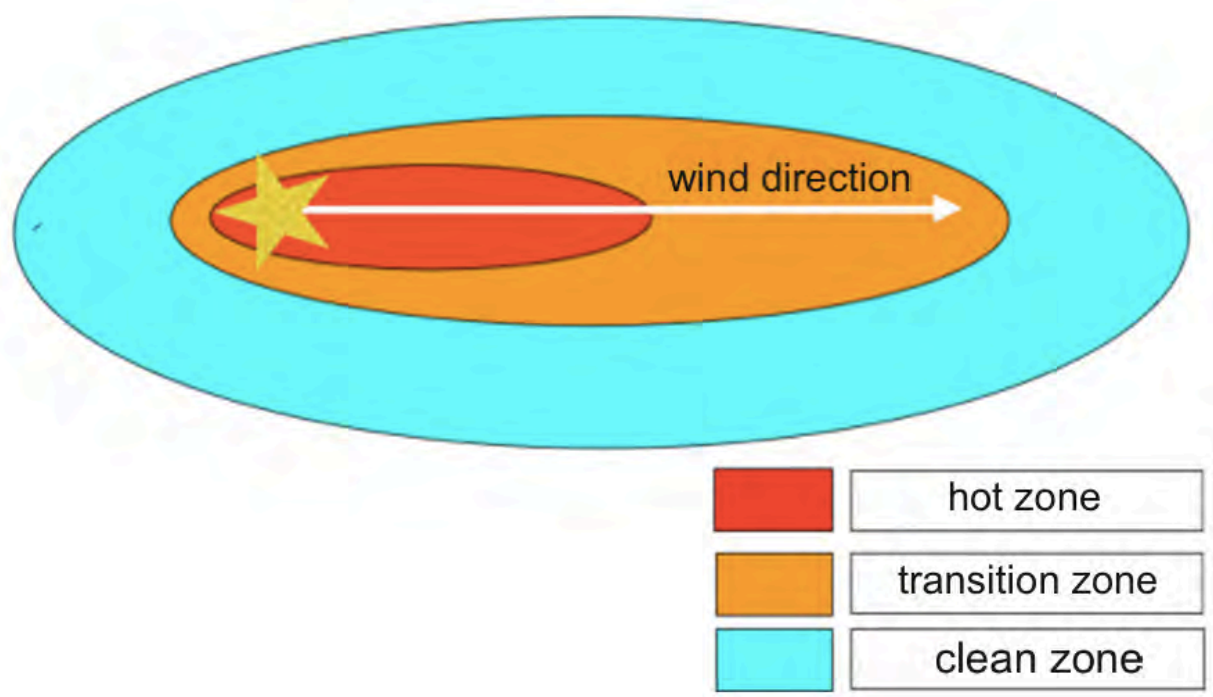

Figure 4. An example of the designation of zones during CBRN counterterrorism activities

After the action, in accordance with good practice, the personnel involved in the handling of the decontamination area first measured the contamination of the body surface of the officers together with the detainees to determine possible contamination. Due to the assumption that application was contaminated in the object being attacked, steps were taken to remove the harmful agent from the body surface of people exposed to it. The whole activity was correlated with protective actions on detained persons and deposited equipment, i.e. firearms, ammunition, tactical equipment. 